\title{
Power Distance between Judges and Witnesses and Judicial Innovations. Preliminary Innovation Ideas from Theoretical and Empirical Research
}

\author{
OÑATI SOCIO-LEGAL SERIES, VOLUME 10, ISSUE 4 (2020), 686-716: INVESTIGATIONS - \\ INVESTIGACIONES - IKERLANAK \\ DOI LINK: HTTPS://DOI.ORG/10.35295/OSLS.IISL/0000-0000-0000-1114 \\ RECEIVED 05 MAY 2019, ACCEPTED 20 NOVEMBER 2019
}

\author{
MichAє DUDEK* (D) \\ MATEUSZ STĘPIEN* ID
}

\section{Abstract}

The aim of the paper is to outline a new original approach to judicial innovations, in comparison to the previous conceptualizations or actual innovation agendas. The proposed approach flows from larger theoretical and empirical project concerned with the reconceptualized, in comparison to Geert Hofstede's, understanding of power distance and its application to courtroom interactions, especially between judges and witnesses. First, the paper carefully clarifies the underlying reconceptualized power distance and empirical research based on it, focused on judge-witness courtroom interactions. Subsequently, the proposed conceptualization of judicial innovations is presented, its assumptions explained and particular examples provided. Against the background of other judicial innovations studies and agendas, it is argued that this

\footnotetext{
The paper was prepared within the research project Dystans władzy na sali sadowej. Studium teoretycznoempiryczne [Power Distance in the Courtroom. Theoretical and Empirical Study] sponsored by the National Science Centre of Poland (Registration number 2015/19/B/HS5/00454). The authors declare their equal contribution in the creation of the paper. They would like also to thank here Anna Drwal and Jan Bazyli Klakla, who co-conducted described observations and interviews, as a realization of their PhD student scholarship position within the mentioned project. A previous version of the paper was presented at the 19th ISA World Congress of Sociology Power, Violence and Justice: Reflections, Responses and Responsibilities, in the session on Judicial Innovation in Turbulent Times: Towards a Redefinition of Power, Quality and Access to Justice? July 15-21, 2018, Toronto, Canada. The authors would like to take this opportunity to thank the organizers and participants for their sincere interest and inspiring comments. They would also like to thank the anonymous reviewers for carefully reading the original manuscript and offering important suggestions, which helped them to improve their argumentation. Naturally, this does not change the fact that only the authors are responsible for all of the possible substantive shortcomings of this paper. ${ }^{*}$ Michał Dudek (PhD in Law) is an Assistant Professor at the Department of Sociology of Law, Faculty of Law and Administration, Jagiellonian University, Bracka 12 Street, room 214, Kraków 31-005, Poland. Email address: michal.dudek@uj.edu.pl

* Mateusz Stępien (Habilitation in Law) is a Professor at the Department of Sociology of Law, Faculty of Law and Administration, Jagiellonian University, Bracka 12 Street, room 214, Kraków 31-005, Poland. Email address: mateusz.stepien@uj.edu.pl
} 
proposal is not only much more theoretically and conceptually clear, but, even more importantly, much more practical, in a sense that it significantly widens perspective on the possible advancements in judicial systems and helps in generating innovation ideas.

\section{Key words}

Power distance; judges; witnesses; courtroom interactions; judicial innovations

\section{Resumen}

El objetivo del artículo es trazar un abordaje original al tema de las innovaciones judiciales, en comparación con conceptualizaciones anteriores o programas reales de innovación. El acercamiento propuesto fluye a partir de un proyecto teórico y empírico más amplio relacionado con la conceptualización, en comparación con la concepción de Geert Hofstede de la distancia de poder y su aplicación a la interacción en los tribunales, sobre todo entre jueces y testigos. Primero, el artículo clarifica cuidadosamente la distancia de poder reconceptualizada subyacente y la investigación empírica basada en ella y centrada en la interacción entre juez y testigo. En consecuencia, se presenta la conceptualización propuesta de innovaciones judiciales, con una explicación de sus supuestos y con ejemplos concretos. Sobre el trasfondo de otros estudios y programas de innovación judicial, se aduce que esta propuesta no sólo es mucho más clara en teoría y conceptos, sino que, lo que es más importante, es mucho más práctica, por cuanto amplifica de forma significativa la perspectiva sobre posibles avances en sistemas judiciales, y ayuda a generar nuevas ideas para innovar.

\section{Palabras clave}

Distancia de poder; jueces; testigos; interacciones en los tribunales; innovación judicial 


\section{Table of contents}

1. Goal 689

2. Rejection of Geert Hofstede's Conceptualization of Power Distance

3. The Basics of Reconceptualized Power Distance.... 690

4. Judge-Witness Relations as Illustration of Reconceptualized Power Distance 692

5. Organizational, Interactional and Subjective (Individual) Levels of

Reconceptualized Power Distance

6. Empirical Research on Power Distance Between Judges and Witnesses. A Brief Presentation

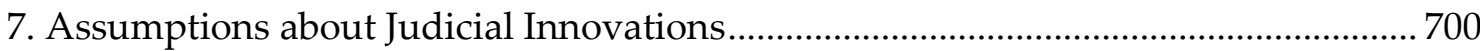

8. Fundamental Innovation and Specific Kinds of Judicial Innovations .......................... 704

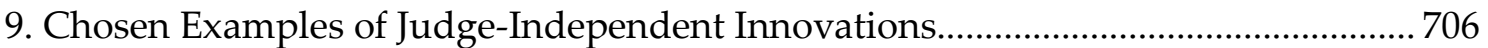

10. Chosen Examples of Judge-Dependent Innovations................................................... 709

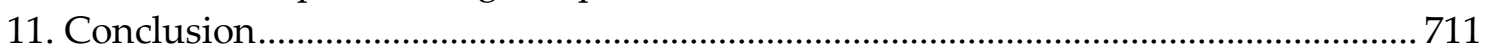

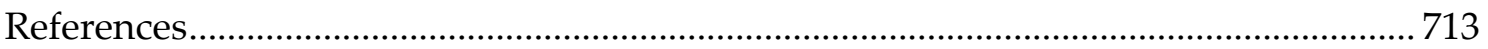




\section{Goal}

The aim of the paper is to present and discuss how original reconceptualization of power distance for the purposes of empirical research in courtrooms can be used as a basis for generating innovation scenarios in courts. It should be stressed, however, that the following is part of a much larger theoretical and empirical project that was devoted to measuring power distance in courtrooms, especially between judges and witnesses. Even though the project was conducted by Polish scholars and the empirical research carried out in a Polish court, the following material is of a general nature and can thus also be applied to other national legal systems. Naturally, before examining how reconceptualized power distance can be used as a basis on which one can generate innovation scenarios for the judiciary, some basic information about the research project referred to above should first be presented. This means that a reader is kindly asked for some patience. Ultimately, this paper identifies some new ways of thinking about judicial innovation. However, before this novel approach is presented and discussed, it is necessary to explain its roots, i.e. the changed concept of power distance and certain empirical research based thereon.

\section{Rejection of Geert Hofstede's Conceptualization of Power Distance}

The notion of power distance coined and elaborated by Geert Hofstede (e.g. Hofstede 2001, p. 98, Hofstede et al. 2010, p. 61) as "the extent to which the less powerful members of institutions and organizations within a country expect and accept that power is distributed unequally"1 has gained much popularity and significance. Even though some attempts have been made to use the power distance category exclusively in the judicial context (e.g. Machura 2007), it is doubtful whether its potential has been completely utilized. Namely, after reconceptualization, the general idea of Hofstede's power distance could be developed in such a way that it encompasses virtually the full range of interactional dynamics between those in power and those subordinated, regardless of the specific organizational context. One should remember that Hofstede's original approach to power distance, which relates simply to the level of expectations and acceptance of an unequal distribution of power, is very general, and these levels can, therefore, be measured in different countries, organizations and people. However, in conceptual terms, Hofstede's power distance can be regarded as an extremely narrow category. It relates only to certain subjective, mental processes that occur in the minds of people who are involved in some relationship in which one party can do more than the other. Moreover, those processes are reduced to the expectation and acceptance levels relating to the inequality of the parties involved; as purely subjective processes, they can, therefore, remain unnoticeable from the outside. Of course, this should not be understood as a statement that power distance in Hofstede's sense cannot be correlated with intersubjectively observable processes or phenomena. The mental expectation or acceptance levels for unequal distribution of power can present certain signs that can be noticed from the outside, but ultimately Hofstede's formula for power distance does not stress this aspect sufficiently. Its emphasis on the purely subjective side of power

\footnotetext{
${ }^{1}$ Here the notion of "distance" should not be interpreted through the spatial connotation of that word, but in a much broader way. The same applies to the introduced reconceptualization of power distance, where the concept itself is broad enough to take into account some spatial courtroom-related issues (proxemics included) as well as other constituents of modified understanding of power distance, discussed below.
} 
dynamics in different contexts (e.g. national or organizational) is also noticeable in Hofstede's original methodology of measuring power distance. It is reduced to three quite straightforward questions relating to whether subordinates are afraid to disagree with those in power and the actual and preferred decision-making styles of the latter.

Taking into account what seems to be implied in the notion of power distance - inter alia that people in organizations have different possibilities of actions with respect to each other, which are ultimately not only subject to certain mental processes but are also differently realized, negotiated or corrected during interactions, which take place not in some vacuum, but in very specific socio-material environments that can significantly influence the power dynamics between the parties involved - the following conclusion was reached. Power distance can and should be reconceptualized with reference to Hofstede's original approach in order to take into account what seems to be implied by the concept itself (see, generally, Nakata 2009).

\section{The Basics of Reconceptualized Power Distance}

The first step in the presented project on power distance in courtrooms, which can also be used as a basis for innovation scenarios for the judiciary, was to develop a new, more capacious approach to power distance. For the sake of this specific paper, it was decided to focus on the most crucial and fundamental assumptions underlying the reconceptualization of Hofstede's notion.

First of all, power is not understood in this project as something that already exists between people and thus able to be distributed among them, with such distribution being the subject of their acceptance or non-acceptance. Instead of assuming that power is something similar to money - or any other value that is, in a way, external to people and can thus be acquired by them and accumulated in various ways - it was decided to adopt a different approach. Drawing basic inspiration from the work on power by the Polish legal sociologist and political scientist Krzysztof Pałecki (2003), power is rather understood as something that is in a constant state of flux. It is not ready-made, but something that happens and changes during an interaction between people.

The crux of this project is, therefore, the assumption that power is an asymmetrical social relation. This implies that there must be a minimum of two human subjects interacting with each other, one of whom is able to do more with respect to the other person than the other can do in response. This asymmetry - one person being able to do more than the other - results from some rule or recognized practice underlying the ongoing interaction. This should be emphasized in order to avoid the impression that such asymmetry is the result of a drastic act, such as a bank robber terrorizing bank employees with a gun in order to get the money from the safe. In the presented approach, power since its basis is located in certain rules or recognized practices - is in strict opposition to violence. However, the following crucial feature of these assumed rules and practices also needs to be addressed.

The underlying rules and practices that ultimately guide the actions of those involved in asymmetrical social relation are not complete, even though they can be quite numerous (for example, in addition to legal rules there can be customary rules, which additionally specify the relation they underlie). They frequently leave certain specific aspects of the interactions they regulate unspecified - empty and open to bargaining. Imagine, for 
example, a fairly basic relationship between an employer and employee in some privately-owned company. The clearly asymmetrical character of their relationship is explainable on the basis of certain underlying rules specifying how interactions between an employer and employee in a specific company should take place. These rules not only come from the individual contract between employer and employee, but also from the more generally valid rules of labor law. However, despite the fact that the underlying rules and recognized practices that are in a way responsible for the asymmetry between the parties in a given relationship can be very detailed, they still do not address every aspect of that relationship. For example, work contracts and labor law regulations can be completely silent on whether employer and employee should refer to each other by their names, or even nicknames, or whether they should be much more formal and official, using terms such as "Sir" or "Madam". Gaps such as these in the rules and recognized practices underlying asymmetrical social relation can, and ultimately are, filled by the individual behavior of the parties in a given relationship. The particular way in which a given gap is filled can either increase or decrease the asymmetry between the parties, thus increasing or decreasing the power distance between them. Ultimately, there is a significant difference between a situation in which an employer and employee refer to each other by their names or even nicknames - it definitely flattens the existing asymmetry - and a situation in which "Sir", "Madam", or other official titles are still in use, often irrespective of the length of time the parties have worked together. The latter can be regarded as simply stressing and highlighting the power differences that originate from the rules or recognized practices underlying the relation in question. Of course, this example holds good only under the assumption that in a given time and space in a given society, there are no social rules other than the mentioned legal ones that specifically address how superiors and subordinates in a given type of organization should refer to each other. In a case of their presence, the already mentioned gap that is usually filled by the individual behaviors of the parties involved would not exist. In light of the above, it should be recognized that in practice the assessment of a given asymmetrical social relationship and whether that which underlies it leaves certain aspects unspecified and thus open to being filled by specific behavior is very subtle and relative.

The final feature of a reconceptualized category of power distance that needs to be addressed here with a view to discussing innovations in courts on the basis of empirical research is the following. Asymmetrical social relations are not abstracted from their surroundings; they all take place in a specific place or setting with its own specific material objects, symbols, or general characteristics. All these features and details, even the tiniest ones, are relevant to power distance. Just as the individual behaviors of parties in a given asymmetrical social relationship can either increase or decrease power distance between them, the surroundings of particular interactions can and do play a similar role. Consider, for example, the differences that exist between managers' desks: one is massive and even intimidating due to its elevation in comparison to the rest of the office and made out of dark wood, while another is much more modest. The former seems to act as a tool to enhance the asymmetry between the person behind the desk and his or her visitors. Naturally, the characteristics of desks in offices is only one example out of a plethora of material factors that can influence power distance. The multitude of factors that can and should be taken into account for the sake of a more in-depth 
understanding of power dynamics include the external and internal appearance of a given building and the rooms within it, the positioning of the rooms in a building, the means of access to them, or the absence or presence of various symbols or personal items relating to members of the organization, such as photographs of family members.

\section{Judge-Witness Relations as Illustration of Reconceptualized Power Distance}

Even though the above section provides only a brief and incomplete account of the reconceptualization of power distance made for the sake of larger theoretical and empirical research project, it nevertheless clearly demonstrates how the general intuition behind Hofstede's notion can be significantly developed and expanded. As stated above, in this particular case the reconceptualization was applied in a judicial context.

Naturally, courts can be regarded as internally very complex and diverse organizations (e.g. Ostrom et al. 2007). Consequently, one encounters many kinds of asymmetrical social relationships between various categories of actors that function within courts. With reference to the realities of contemporary Polish courts, one could consider, for example, the power distance between judges and clerks, attorneys or prosecutors. However interesting and important such relationships may seem to be, this project focused on one particular kind of asymmetrical social relationship, which takes place in courtrooms during case hearings: the relationship between judge and witness, especially when the former is questioning the latter. It should be stressed here that civil and criminal proceedings in Polish courts are based on the inquisitorial model, as opposed to the adversarial model. In other words, the role of a Polish judge in the courtroom is much more active, especially with respect to witness, than, for example in the United States (for more on the comparison between Polish inquisitorial and American adversarial procedures, see Bednarek 2014). The judge not only listens to the witness cross-examination conducted by the parties to the case, but is, in fact, the first person to question the summoned witness, often in a very detailed manner. Having clarified that, it is also necessary to explain the choice to focus on the judge-witness relationship in this project.

First of all, especially in the context of Polish legal science, there is a noticeable lack of empirically grounded research on witnesses in courtrooms. Moreover, researching witnesses during hearings, especially in the lower courts, is a significant opportunity to try to understand how laypeople experience courts and ultimately what influences their opinions and attitudes towards the judiciary. Frequently, people have the opportunity to be in a courtroom only once in their lives, when summoned as witnesses (according to the 2017 CBOS report on a public opinion study on a representative sample of the adult population of Poland, $60 \%$ of respondents claimed that they had not had any contact with courts in the past five years, and neither had their friends or relatives). Taking a closer look at such contact between judges and witnesses - i.e. the fact that this is very often the first time that a layperson has ever been in court and before a judge enables a better understanding not only of the functioning of the judiciary, but also of how social opinions of the latter are developed and changed.

As already stated, the social relationship between a judge and a witness being questioned in a courtroom is asymmetrical. A judge can do more with respect to a 
witness than a witness can do in response to a judge, and that is due to the existence of underlying rules and recognized practices relating to the way court hearings are conducted. The witness is supposed to stand still behind a dedicated spot in the courtroom, while the judge sits in a judge's chair. Moreover, the witness is supposed to answer questions of the judge, and not to ask questions herself or himself. These and many other aspects of asymmetry in the judge-witness relationship are grounded in many sources - for example, codes of proceedings, court regulations, or even handbooks on the methodology to be applied by judges (e.g. Świecki 2012, Bladowski 2013, Samborski 2013, which include remarks on how judges should behave in offence, civil or criminal cases). These rules and practices often seem very detailed, yet they make no reference whatsoever to details of face-to-face judge-witness interaction such as gestures, eye contact, facial expressions, voice volume, use of specific words, or even length of speech (all subjects of numerous studies concerning the verbal and nonverbal behavior of judges; see, for example, Burnett and Badzinski 2005, and the literature quoted therein). On the basis of these and other aspects of ongoing interaction, the actors involved - in this context, judge and witness - can increase or decrease the power distance between themselves that already exists on the basis of the rules and recognized practices underlying their relationship. Naturally, such an increase or decrease can occur through different and often very subtle verbal or nonverbal behaviors undertaken within the aspects of interaction mentioned above. For example, if a judge maintains eye contact with the witness during questioning, smiles in an honest manner and nods, this could be regarded as reducing the power distance, thus making the witness's appearance in the courtroom easier and less intimidating. On the other hand, a judge with a focused but expressionless face who constantly uses legalese when questioning the lay witness - while at the same time rarely looking at him or her - could be regarded as increasing the existing power distance.

These and other judge-witness power distance fluctuations should not be regarded merely as parts of interactional courtroom dynamics. They can have different consequences for other aspects of a broadly understood judiciary. First, different power distance levels reached during witness questioning have an impact on whether and precisely how particular procedural principles are realized. For example, the principle of the impartiality of court proceedings seems to go hand in hand with increased power distance levels, whereas the principle of the humanitarian treatment of participants (generally speaking, respecting their dignity) in court hearings seems to be somewhat correlated with decreasing power distance. ${ }^{2}$ Moreover, one could assume at this point that the power distance dynamics between judges and witnesses can have an influence on how satisfied the latter feel with the court hearing. Logically, then, it can be said that power distance has an impact on how judges are perceived in society and on general social attitudes to the judiciary. If a particular witness in a courtroom experienced a series of behaviors by the judge that significantly reduced the power distance between them - and if that general decrease was perceived positively by the witness - then he or she will leave the courtroom with a more favorable opinion of judges and courts than

\footnotetext{
2 Referring to such narrowly understood principles of court proceedings, it must be stipulated at the outset that distinguishing many various principles to be implemented in courtrooms is characteristic especially for continental European countries of civil law, to which Poland belongs. In comparison, in the commented context, common law seems to be much more holistic, as illustrated by the due process principle.
} 
before the hearing. Of course, such an outcome is possible under (at least) one very specific condition. In order to positively evaluate aspects of the behavior of the judge that ultimately reduce the power distance between the latter and oneself, one has to have a general preference for flattening the asymmetry between oneself and the particular person in power. By contrast, when a specific actor - in this context a witness - has a preference for upholding or even highlighting the asymmetry of the relationship in which he or she is participating, the decrease in power distance made by a judge's specific behaviors could be perceived negatively - for example as being unworthy of the seriousness of judge's function and role. Naturally, if witnesses with a preference for greater power distance happen to be questioned by a judge who is reducing the power distance, then one would expect such witnesses to be dissatisfied with the hearing and to have more doubts or even outright negative opinions of the judiciary. That is one of the reasons that judges should not only be made aware of the aspect of power distance in their work, but should also try to approach their own behavior in the courtroom more reflexively - even with regard to the tiniest details, which may seem irrelevant to the application of law. This general remark - which constitutes one of the basic ideas for innovations in relation to courts and judges on the basis of power distance research - is developed below. First, however, it is necessary to highlight certain theoretical points relating to the reconceptualized power distance category and to say something about the empirical research grounded in it.

\section{Organizational, Interactional and Subjective (Individual) Levels of Reconceptualized Power Distance}

In light of the above discussion, it should be stressed that the notion of reconceptualized power distance is regarded as being constituted of three distinguishable levels or layers. First, one should recognize the organizational level of power distance. This is the level of rules and recognized practices, but also of other factors that ultimately underlie a given asymmetrical social relationship, or even, one might say, cause the very asymmetry itself. At the organizational level, power distance comes from specific regulations, recognized practices, or rituals, but also from the architecture or spatiomaterial surroundings in which a given relation is supposed to take place. In the specific context of this paper, the organizational level of power distance is composed of or, to be more precise, determined by codes of proceedings, court regulations, widely recognized practices and rituals of conducting hearings and their spatio-material aspects (e.g. Mulcahy 2011); from court buildings and their appearance, through courtrooms, how they are arranged, and particular objects within them - such as national emblems, microphones and cameras - to the judge's robe and chain. Moreover, the organizational level of power distance understood in such a way is relatively independent of the actors involved in a given relationship. In the judicial context discussed here, it means that judges, witnesses, plaintiffs, prosecutors, clerks, or other people involved in the courtroom interactions simply cannot change that which underlies the relationships in which they participate. Ultimately, even judges have to work in a given building and particular courtroom and follow specific regulations. It is the same in the case of other participants. Certain general aspects of what goes on in court, and in courtrooms in particular, are predetermined, which means that parties to the case, their lawyers, prosecutors, and the summoned witnesses have to follow them. 
However, as stated above, the factors underlying an asymmetrical social relationship do not refer to every single aspect of it. Consequently, the parties involved can - through their own behaviors with respect to one another - either highlight and increase the asymmetry present at the organizational level or reduce it, flatten it, and make it less evident, thus increasing or decreasing power distance. In order to address this, it is essential to distinguish a second level of reconceptualized power distance: interactional. This refers to various changes in power distance - in comparison to its basic form determined at the organizational level - that result from the actions of the people involved in a given interaction. As stated earlier, details of courtroom interactions such as eye contact or voice volume are not specified at the organizational level, and these gaps are, therefore, filled by the actors involved. Their actions in these and other aspects result in a power distance that is lower or higher than the distance already established at the organizational level. ${ }^{3}$ In conclusion, at the interactional level, power distance is no longer a social relationship feature that is outside the reach of its parties, but actually is a consequence of their actions. In other words, the way in which particular participants in a courtroom hearing behave - in the context of this presented research, judges and witnesses - determines the power distance between them. Its organizational level is fundamental, but it does not determine it completely. In a certain sense, power distance is fulfilled at the interactional level - a level that is made up of a plethora of specific actions, often very subtle ones.

The above needs to be qualified by the following reservation. Power distance at its interactional level is determined by both deliberate, reflexive choices of particular actions made by the parties, as well as by certain behaviors that can be regarded from the perspective of the actors that display them as indeliberate and irreflexive. To substantiate this, consider the following not uncommon situation, when one person involved in an interaction misinterprets the general mood, attitude, or intention of the other party, because the latter, for example, made specific facial expressions. When confronted about that, the person concerned honestly denies that he or she was actually displaying the mood, attitude, intention, or emotion inferred by the former party, with the words: "I was not aware I was doing that. No, everything is fine. Please, do not get me wrong". Taking into account similar situations, one should recognize that power distance at its interactional level is very sensitive. It can be significantly changed because of certain noticeable but ultimately unintended aspects of behavior of some party. Moreover, such a change in power distance can be in conflict with the original plan or intention that the given party had in mind. For example, a manager who wants to be perceived as easy-going and as a partner among his or her subordinates can fail to achieve that because of, for example, some nonverbal feature he or she is not even aware of. In order to avoid such situations and to reflexively, deliberately and successfully

\footnotetext{
${ }^{3}$ In consequence, one can say that proposed reconceptualization of power distance takes into account broadly understood behavioral deviations from some external factors that generally impose some structure upon actions of individuals, like architectural and spatio-material surroundings, rules, rituals and other constituents of the mentioned organizational power distance. In accordance with the reconceptualized power distance, different and relatively standardized ways of acting with respect to other people in particular contexts (i.a. interaction rituals) should be treated as nothing more than a starting point in analyses (not their exclusive object), that should deal with how the gaps in these ways of action are fulfilled by people involved in a given interaction and how such gap-filling influences the asymmetry between the interactants.
} 
manage power distance at an interactional level, it seems one has to become more selfaware about one's behavioral patterns and, if necessary, try to change them.

The above also applies to the context of this specific research on power distance between judges and witnesses in the courtroom. If the realization of some principles of proceedings or social evaluation of judges and attitudes towards them can be regarded as dependent on the power distance actually achieved during a court hearing, then judges should also think more carefully about how they behave in courtrooms. They need to take into consideration how they can be perceived by other participants, including questioned witnesses, how they would like to be perceived, what aspects of their behavior they should change, and precisely how they should reclaim control over such aspects that they were not aware of, but may still be important to power distance and its further consequences. As will be stressed below, this way of thinking and what it implies for judges themselves - and the improvement of the judiciary in general - can be regarded as a fundamental innovation that emerged from the research project referred to earlier.

There is still, however, a third level of reconceptualized power distance that needs to be clearly distinguished, namely the subjective (individual) level. As suggested above, one can make the assumption that every person has certain personal preferences concerning asymmetrical social relations. Both those who have the power in a specific context, as well as those subordinate to them, can be regarded as having certain ideas of how a given relationship or a particular interaction with the person subordinate/superior to themselves should unfold. For example, some people may simply prefer maintaining or even stressing the differences between the parties involved, while others may prefer reducing or flattening such differences. Consequently, there are people who subjectively (individually) prefer a high distance, as well as those who prefer a low power distance. Moreover, people seem to evaluate the interactions in which they participate and the other parties in them in accordance with these preferences. Consider, for example, the case of a summoned witness who subjectively prefers that those in power should stress their position in the face of subordinates. When such a person is questioned during a case hearing by a very easy-going, approachable judge who is certainly not intimidating, he or she could experience disappointment, in the sense that the interaction with the person wielding the power - the judge - did not meet personal expectations. The interactional level did not match the subjective (individual) one. This specific power distance dissonance can, in turn, lead to a negative opinion about the particular judge for example, that he or she was not behaving seriously enough. Of course, the reverse situation is also possible. A witness with a low subjective power distance who is questioned by a judge who significantly increases power distance at the interactional level could form a negative opinion about that judge. However, in this case such a negative opinion could take on a specific form - for example, the witness complaining about stress or intimidation caused by the judge, or even his or her arrogance.

Having said that, one could venture the following statement. Those judges who wish to improve social opinions and attitudes towards the judiciary should adequately adjust their own behaviors during case hearings to the subjective power distance levels of participants, including witnesses. Otherwise, judges' behaviors and their influence on interactional power distance will not meet the participants' expectations in the form of 
subjective power distance, thus provoking negative opinions and attitudes. Of course, the idea of such adjustment is controversial, to say the least, especially from the perspective of judicial impartiality. However, when one takes into account other values that are or may be highly relevant for the judiciary (such as humanitarian treatment of case hearing participants - respecting their dignity - or, in the face of poor social opinions about judges, the need to improve social reception of judiciary), this suggestion stops being so easily dismissible. Leaving this particular controversy aside, it is enough to say that the final, subjective (individual) level of reconceptualized power distance also suggests certain novel ways of thinking about courts, judges and social opinions about them. These, in turn, could be developed into innovation scenarios for a broadly understood judiciary, some of which are elaborated on below.

At this point it should be noted that the subjective (individual) level of power distance is the one which corresponds best to Hofstede's original idea - i.e. specific personal expectations concerning the superior-subordinate relationship. However, in this study reconceptualized power distance is not only a mental process; it is a much more complex phenomenon, which ultimately consists of the most basic organizational level. Its gaps and omissions are variously filled by the actions of people involved in a given relationship, at the interactional level. The actors involved not only increase or reduce the basic power distance established by the underlying rules, practices or other objective factors; they also submit the ongoing interaction and its various details to their personal evaluation. This is done in accordance with their personal preferences for low or high power distance, at the subjective (individual) level. Naturally, this three-level, compositional reconceptualization of power distance does not presuppose a coherence between these three levels. It enables then to address the fluid dynamics of the phenomenon. As stated earlier, this illustrates how narrow Hofstede's original approach is and how it can be expanded in such a way that completely new and promising research perspectives emerge. ${ }^{4}$ Naturally, the briefly presented reconceptualized power distance with its organizational, interactional and subjective (individual) levels can be applied to different kinds of asymmetrical social relationships, but in the case of this research, it was used to address the judge-witness relationship during case hearings in the contemporary Polish judicial system. As stated earlier, this research was not only theoretical and conceptual, but also empirical. A brief reference to the empirical research is needed here, because it was here that the issue of innovations stemming from the reconceptualized power distance was addressed.

\footnotetext{
${ }_{4}^{4}$ For instance, John M. Conley and William M. O'Barr's (1990) distinction between rules- and relationshiporientation can be compared with subjective preferences for high or low power distance, but it would be superficial to simply identify these two with each other. In the end, rules-oriented hearing participants are supposed to be focused on legal formalities to such extent that they are ultimately irrespective of social statutes. In comparison, the proposed reconceptualization of power distance does not rest on such strong analytical opposition of rules and statuses. According to the proposal and the level of organizational power distance, one can say that to a certain extent one's status is dependent on rules, legal rules included. Moreover, the presented approach to power distance is a holistic framework - it allows to take into account not only personal attitudes and verbal behaviors (that seem to be the main interest in Conley and O'Barr's popular framework), but also nonverbal behaviors, extraverbal factors (like clothes) and even the architecture or broader spatio-material surroundings, not to mention the black-letter regulations.
} 


\section{Empirical Research on Power Distance Between Judges and Witnesses. A Brief Presentation}

Having completed the power distance theoretical reconceptualization, research team members decided to commence empirical research on the basis of the following question: "What is the power distance between judges and witnesses, and does it influence the broadly understood level of satisfaction that witnesses experience from a hearing; if so, in what way?". To address this question a combined methodology was adopted, consisting of both passive observation of hearings and semi-structured interviews with witnesses, conducted immediately after they had been questioned in the courtroom. This dual research was undertaken in Kraków's (Poland) Lower Court. First, a pilot research was conducted in November and December 2017 during which research team members attended various hearings in Kraków's Lower Court - civil, criminal, and offence cases - and made unstructured observations in the courtrooms, focusing on the judge-witness interactions. This pilot research facilitated not only the development of a dedicated observation questionnaire, but also the preparation of a semi-structured witness interview questionnaire. On the basis of these two tools, proper research commenced at the same court, spanning the period from January to the beginning of July 2018.

The research was undertaken in the following manner. On a couple of days of nearly every week one research team member attended various court hearings as an audience member and used the special questionnaire to record their observations, with an emphasis on judge-witness dynamics. Notes were taken, for example, on whether and how the judge welcomed the witness in the courtroom, whether the judge corrected the witness in some manner, and vice versa, and - more generally - how the judge and witness behaved verbally and nonverbally with respect to each other during the questioning of the latter. In addition to such purely interactional issues, the more objective, organizational aspects of the proceedings as a whole were also taken into account during observations. For example, notes were also taken about the courtroom's general appearance and specific aspects. ${ }^{5}$ While the first research team member was observing, the second team member was waiting outside the same courtroom to interview the witness who had just been questioned (on the simultaneous use of two researchers, but during observations, see Roach Anleu et al. 2016). As soon as the witness left the courtroom he or she was approached by the second research team member and asked whether he or she would like to take part in an academic research project by answering a few basic questions about the hearing and the judge's questioning. In accordance with the interview questionnaire, questions were asked about, inter alia, previous participation in case hearings, general satisfaction with the current hearing, and - last but not least - the judge's behavior: the witness's opinion of it, what was good or bad about it, and whether there was anything missing from it.

Research combining these two specific methods over the entire length of the process enabled the collection of significant amounts of descriptive, ethnographic data about courts, courtrooms and the interactions within them. However, it also was meant to

\footnotetext{
${ }^{5}$ It explains why research team members did not ground their research in popular frameworks used to studying courtroom interactions like ethnomethodology or conversation analysis. Namely, they did not focus exclusively on people participating in a given interaction and their behaviors.
} 
confront two different kinds of collected data with one another: observations of case hearings with special emphasis on judge-witness interaction and witnesses' opinions about the questioning and judges collected immediately after witnesses left the courtroom. A detailed discussion of the results of this research and a methodological self-reflection after its completion are beyond the scope of this paper. Nevertheless, the results did lead to a number of interesting conclusions. It can be said that, in general, power distance between judges and witnesses is already relatively high at its most fundamental organizational level, and it is, therefore, easier for judges to reduce power distance at the interactional level. Moreover, an examination of the observations and interviews demonstrated that while many behaviors of judges may raise certain doubts about their appropriateness or admissibility, most of the witnesses were relatively satisfied with how they were treated by judges, even when their behaviors were, for instance, yawning; bored and irritated voice tone; raising voice volume, even shouting; constantly interrupting the statements of other participants; unfaithfully dictating the contents of minutes; not apologizing for even considerable delays in beginning of a case hearing; or even loudly hitting the desk with a hand. Moreover, in most cases these behaviors could not be justified by, for instance, unsuitable behaviors of other people in the courtroom. In consequence, these mentioned examples can be regarded as controversial and wrong not only when seen from the perspective of more general, not explicitly law-related principles of well-mannered interpersonal communication, but also from the perspective of such legal principles like judicial impartiality, respecting dignity of case hearing participants and dignity of court as an entire institution. Still, most of the interviewed witnesses appeared to be generally satisfied.

This noticeable discrepancy of opinion can be addressed in a number of different ways. For example, one might say that due to the cognitive overload connected with being a witness and the stress of being questioned in a courtroom, witnesses simply did not notice many aspects of judges' behavior; which is why they were mostly positive about them, even though some details of their work could be regarded as controversial, to say the least. There is also another possible explanatory hypothesis, which is interesting. It could be said that those witnesses who were generally pleased with the judges' behaviors - which ultimately were not unquestionable - could be regarded as having a preference for high, emphasized power distance, in the sense of its subjective (individual) level. Unfortunately, since the corridors in the court building proved to be too uncomfortable for conducting longer, more substantive exchanges, during the interviews that were conducted it was impossible to employ additional research tools that would have made it possible to measure witnesses' own subjective (individual) power distance. As a result, the combined methods of passive observation and semistructured interviews could not provide a conclusive answer concerning the presumed connection between judge-witness power distance and broadly understood satisfaction of witnesses.

Again, this paper is not the proper place to discuss at length how that problem was specifically addressed by research team members and to what other kind of empirical research it eventually led. In the context of this paper, the following is more important. Even though the discussed research on power distance between judges and witnesses may at this point seem to be a purely descriptive study - a kind of diagnosis of a specific aspect of a broadly understood judiciary - it also possesses a certain significant 
prescriptive character. As was said earlier, reconceptualized power distance can be used as a basis from which to derive certain innovation scenarios for judicial systems, courts, courtrooms, and indeed for judges and their work. In fact, the issue of innovation was not only addressed during the initial theoretical stages of work on the presented project, but was also consistently kept in mind by research team members during observations and interviews in the form of the following question: "Can reconceptualized power distance be the basis for judicial innovations, and if so, in what sense and for what specific innovations?". The repeated visits to courts and various courtrooms during different case hearings allowed the research team members to notice different aspects of the judiciary (for example, normative, organizational, spatio-material or architectural, technological and behavioral aspects), connect them with the assumed reconceptualized power distance and its further effects or implications for such significant issues as the realization of procedural principles or social attitudes towards courts and judges.

Apart from the original questions posed by research team members in the course of their project, the presented reconceptualization can be used in many ways, for instance: comparing with other possible approaches in courtroom interaction research; studying courtroom power distance in different countries (international/inter-jurisdictional comparative research); or diagnosing some socio-demographic factors influencing power distance (like who, in general, increases the power distance more - male or female judges, or younger or older judges). However, the aim of the paper is purely illustrative - to show what kind of innovation scenarios can be generated on the basis of the conducted research or, more generally speaking, to present how reconceptualized power distance can fuel thinking about judicial innovations. Having explained the necessary basics of the research project on power distance between judges and witnesses, one can now move on to the subject of judicial innovations that can be derived from it.

\section{Assumptions about Judicial Innovations}

Before there can be any valuable discussion about potential innovations for the judiciary, courts and judges as a result of a reconceptualized notion of power distance it is first necessary to define and clarify what judicial innovation is (on the complicated history of the notion of innovation, see Godin 2015). For the purposes of this research project, judicial innovation is understood as a deliberate, considered change (compared to the past) that leads to improved functioning of the judiciary, understood in a broad sense, especially in relation to a more efficient realization of procedural principles (for example, impartiality, independence or humanitarian treatment) or enabling development and maintenance of positive attitudes towards the judiciary in society. Ultimately, courts and judges do not function in a social vacuum, and the realization of their institutional goals or principles is, therefore, to a certain extent, dependent on how ordinary people approach the judiciary. ${ }^{6}$

\footnotetext{
${ }^{6}$ Defining innovation in public sector organizations, to which courts and entire judiciary undoubtedly belong, in general, theoretical terms seems to be inherently riddled with difficulties. In comparison, for instance, with simple private sector business organization, which by definition may be focused only on a financial profit and market share increase, judicial system organizations in practice have to realize many different goals that often do not go hand in hand. One should acknowledge this easily, especially when one adopts a civil law perspective on courts' responsibilities, referred to earlier. For example, judicial impartiality should be realized consistently every day, dignity of court as an institution should also be
} 
However, one can also discern certain possible tensions between the aspects mentioned above. For example, an improved realization of the impartiality principle through the implementation of a specific innovation can, under certain circumstances, lead to a worsening of attitudes towards the judiciary in some parts of society. Ultimately, in the eyes of certain people, an impartial judge can be regarded as significantly lacking in human sensitivity. The possible relations between the two main points of reference of judicial innovation should be then taken into account as well - not only for theoretical reasons, but, more importantly, for practical ones. They can and should be assessed in advance, and specific ideas of judicial innovations should be carefully evaluated in terms of such a diagnosis. This would make it possible for the safest option to be selected when a choice is to be made from among the many different innovation ideas concerning a given issue - an option that properly balances the realization of principles with the question of social opinions. Naturally, this idea of balancing can be criticized as too vague and, in fact, impractical. However, it is addressed here not in a sense of a readyto-use clear practical instruction, but merely as a part of the proposed understanding of the concept of judicial innovation.

Obviously, the above is not the only implication of the understanding of judicial innovation that has been presented. In light of it, it should be quite clear that not all changes that take place in the judicial system in general - and in the operation of courts and judges in particular - can be regarded as judicial innovation. It is not something accidental - to deserve its name, innovation has to have some reflexive actor behind it. As will be stressed below, that actor does not have to be the macro-level legislator, or the meso-level court director or manager. Individual judges can also be agents of change for the better, even though they can be regarded as micro-level actors. Moreover, as may have been surmised in light of the previous discussion on power distance - especially its subtle interactional level - significant attention is given to judges and their behavior in the courtroom in the proposed approach to judicial innovations. It flows from the assumption and at the same time strong conviction established during observations and interviews that micro factors - especially various aspects of judges' behavior in the courtroom - are in fact crucial for the realization of the judiciary's goals. This perspective and focus - which are perfectly consistent with the theoretical and empirical part of the discussed project - lead to the following consequences.

The developed approach to judicial innovations here is quite different from many other studies on innovations in courts and in the work of judges. Innovation ideas following power distance research in no way focus on normative, black-letter law-based changes concerning the operations of courts. One could even say that reconceptualized power distance and the research based on it that has already been undertaken seem, above all, to suggest subtle bottom-up changes in the functioning of courts and judges, and not only general top-down innovations initiated at the level of national legislation and ministries of justice. Moreover, against the background of many judicial innovation

upheld even in the face of most difficult situations that can happen in courts and courtrooms, but at the same time ordinary people's dignity should not be impaired in them. When one adds to these exemplary concerns of courts that have some grounding in valid black-letter regulations, the issues of social opinions about judiciary, the multitargeted nature of responsibilities and operations of courts should be easily recognizable. The proposed general understanding of judicial innovation aims at addressing this multifacetedness. 
studies and actual innovation agendas, the approach proposed here does not focus on technologically based changes. On the contrary, the theoretical and empirical parts of the power distance research project seem to lead inevitably to the conclusion that one can make a significant difference for the better in the judiciary with really modest means that are not spectacular in any way (which can be regarded as generally consistent with the systems thinking applied to organizations, see Senge et al. 1994, Senge 2006). To substantiate this and the previous point about the lack of focus on normative changes, it should be borne in mind that under specific conditions a significant change in the social perception of judges could be brought about by something so simple as judges reducing power distance through the use of easier, more everyday vocabulary during case hearings - especially when interacting with laypeople. Consequently, it could be added that the standpoint adopted here on judicial innovations does not focus exclusively on a meso-level managerial approach to initiating changes by, for example, court directors or administrators.

Of course, as will be demonstrated below, certain innovation ideas derived from reconceptualized power distance not only can, but have to be normatively, technologically, or managerially mediated. However, the notion of judicial innovation that stems from the significantly altered concept of power distance appears to be much wider and more extensive, in the sense that it does not stop at macro- or meso-level innovations. It has a significant advantage over other approaches to judicial innovations, in that it allows the wide array of verbal and nonverbal behaviors of judges, with all their subtle aspects, to be seriously recognized as areas where judges themselves can introduce changes, even completely independently of the possible innovation agendas of the legislation or court administration levels. To put it differently, the proposed approach restores for judges their own agency concerning judicial innovations, an aspect that often seems to be neglected in many studies and agendas.

Bearing all of the above in mind, it should be pointed out that the way of thinking about judicial innovations elaborated here is based on two further assumptions: first, drawing careful inspiration from the broad organizational sciences, including those concerned with the judiciary, and second, being quite suspicious about insiders' perspectives on their own organizations. The former is already evident in the way Hofstede's original conceptualization of power distance was treated, as well as its other developments and modifications. The latter, on the other hand, can be discerned in the briefly described methodology of empirical research in Kraków's Lower Court.

The above research was focused on gathering witnesses' opinions on what had just happened in the courtroom. Naturally, the fact that there were no discussions with the judges themselves or with other insiders of court chosen for the research can be regarded as a significant gap in the project. However, it was perfectly consistent with the main research question underlying the observations and interviews. Moreover - and this is even more important in the context of judicial innovations - the interviews were conducted with people who, in most cases, were appearing in court for the first or second time in their lives; attempting to understand their points of view enabled a very fresh perspective to be gained on what can be changed in courts. One could venture to say that a perspective gained in such a way could be regarded as much broader than innovation ideas potentially proposed by court employees. The everyday work of such 
employees could significantly inhibit their own innovativeness and even their attitude to certain change scenarios that they could easily dismiss with words such as "that won't work" or "we do not have time for that". As will be demonstrated below, the discussed approach to judicial innovations emerging from reconceptualized power distance and related research can be regarded as a kind of heuristic device to generate ideas and expand thinking about innovations beyond the usual borders and the work-induced inhibitions among some insiders. Before that, however, one has to stress the final crucial assumption of the discussed approach and demonstrate, on the basis of various examples, that it is quite different from other contributions to the discussion on judicial innovations.

In order to start actually changing something - hopefully for the better - in a considered, deliberate, reflexive way, it should be obvious that a change in mindset first has to happen. Bearing that in mind, even the mere popularization of an idea which itself can be considered as novel and original, could be regarded as innovation as well. In other words, what often seems to be absent in other judicial innovation studies and agendas is an explicit recognition that something as relatively non-spectacular as providing members of the judiciary with a new conceptual framework on the basis of which to think about their work and responsibilities and how to realize them more effectively also deserves to be called innovation.

It should be noted that the above is still only about certain assumptions about judicial innovations underlying the proposed approach. Nevertheless, when one takes some time to review the literature on judicial innovations (of course, not in the same sense as the concepts of judicial activism or judicial law-making, e.g., Clarke 2014, de Londras 2017), it becomes clear that the framework presented here already distinguishes itself at the level of assumptions and drawing on established concepts of social sciences from the rest of the relevant discussion. For example, in reference to the criminal justice system, one can find interesting proposals to move from an individual offender focus in courts to a more expanded problem-solving approach (Freiberg 2004; on therapeutic jurisprudence as a relatively popular framework for judicial innovations, but still not specifying explicitly the adopted understanding of judicial innovation, see Richardson et al. 2016); or even, more generally, when it comes to reforms to place the emphasis on fairness, the people involved in the cases, authority, and speed of proceedings (Bowen and Whitehead 2013). However, one still has to guess the underlying understanding of judicial innovation in general; its definition is not explicitly provided, and ultimately one has to infer it from the course of the argumentation. Similarly is in the case of innovation discussion which relates to even narrower parts of legal systems than criminal justice for example, family law (Eisenberg 2016) or judicial improvements based on information technology (Lepore et al. 2012). The lack of an explanation of the mere notion of judicial innovation - not to mention frequent lack of a clear presentation of assumptions underlying a given standpoint, distinction criteria for different kinds of innovations, or defined starting points from which particular ideas are generated, is noticeable also in more general discussions on novel ideas, which do not focus on specific parts of the legal system (e.g., Miller 2015, Barendrecht et al. 2018, de Savornin Lohman and van Straalen 2018). Generally speaking, therefore, it seems that it is much more common to talk about judicial innovations and address them from the perspective of their points of reference - the specific part of the judicial system to which a given idea refers - than to clarify, in 
general terms, what judicial innovation actually is in the first place; or, more specifically, the precise theoretical point of departure from which these ideas have originated (it is also valid with respect to some of the studies on judicial reforms, e.g., Botero et al. 2003, including more classical and influential analyses as well, e.g., Feeley 2013). The difference between these approaches to judicial innovations and the proposed approach will become even more evident as one moves from the assumptions to the actual innovations themselves.

\section{Fundamental Innovation and Specific Kinds of Judicial Innovations}

In light of the above assumptions, it could be stated that the most fundamental innovation that emerges from the described research can be regarded as purely mental (intellectual), as it consists of the following few theses. First of all, the research project presented provides members of the judiciary with a novel idea, i.e. that something like power distance exists. Reconceptualized power distance is not merely a purely conceptual framework that can be used only to provide a different perspective on certain judicial activities; rather, it is an actual phenomenon that is very significant for the realization of specific procedural principles, for attitudes towards the justice system in general, and towards judges in particular. Becoming aware of it is already an additional tool that can assist in achieving some of these goals in an improved, more efficient and less haphazard way. Ultimately, as suggested earlier on, power distance can be purposefully and reflexively managed (decreased or increased) by specific actors and with the use of different tools. With reference to the already mentioned three levels that constitute reconceptualized power distance, especially the organizational one, it could be said, for example, that legislatures with their amendments to some procedural law concerning case hearings, court building designers with their materialized blueprints of court exteriors and interiors, or court directors or managers who influence the work organization in their courts actually manage and modify the basic organizational level of power distance. In all probability, they all do so without even being aware of it. Making them more aware of certain specific yet crucial implications of their own work is definitely a valuable and needed enterprise. A similar situation applies in the case of individual court employees, especially judges, whose verbal and nonverbal behaviors, in their whole complexity, consistently co-determine power distance at the interactional level during various interactions in the courtroom. Again, as was said earlier, even the most subtle aspects of a judge's behavior, when taken together, can play a significant part in realizing certain principles, or in developing and maintaining particular attitudes towards the judiciary. Needless to say, the latter can have their own impact on the further functioning of courts, and the factors that gave rise to them should, therefore, also be of interest to individual judges.

Naturally, the above discussion of fundamental innovation is only a starting point from which to generate certain innovation ideas for the judiciary. From the general novel assumption that power distance exists - which is important for many goals and outcomes of the judiciary and can be managed by various actors in different parts of the judicial system as a whole - one can and should draw more specific ideas that can be realized in practice. A basic understanding that judicial innovation is a deliberate change (compared to the past), resulting in an improved judiciary - especially in the sense of the realization of procedural principles or the development and maintenance of positive 
social attitudes towards the judiciary - leads to the following. Judicial innovation also proves to have a structure that consists of various levels or layers. It is not only some novelty implemented as a change from the past, but it also relates to that which gave rise to it - i.e. some idea behind it that gave it a beginning and put it in motion - and that which succeeds it, i.e. the actual improvement in some specific relevant aspect. To fully deserve its name, then, all three basic distinguishable levels should actually be realized in conjunction with one another. There should be some underlying idea that is subsequently put in motion and ultimately proves to work as intended. Naturally, one can also examine what kind of improvement should be achieved in order to speak of innovation in the correct sense of the term; in other words, whether any advancement can be regarded as innovation, or only a significant advancement. Leaving this specific issue aside, one should stress here the important consequence of these remarks for the rest of this paper. From the adopted point of view, it should be obvious that the discussion below relates to certain ideas of innovations that can be inferred from the described research on power distance, rather than to actual innovations. In order to be able to talk about specific innovations, one has to refer to novel ideas that were put into practice and ultimately led to the achievement of certain goals. However, in view of limitations in terms of space, the terms "innovation" and "innovation idea" are used interchangeably in the rest of this paper.

The observations and interviews with witnesses referred to earlier made it possible to identify many potential areas for specific innovations, all of which can be connected to reconceptualized power distance. Before discussing some of them with a view to demonstrate how a modified notion of power distance can inspire and fuel thinking about judicial innovations, it seems valuable to identify certain more specific criteria for comparing different kinds of innovations.

As suggested earlier, one can distinguish between innovations that require some normative, procedural or material changes in black-letter law and innovations that do not require explicit legal mediation. In addition, a very important distinction is that between innovations that are ultimately independent of judges' individual behaviors and innovations that simply cannot exist without judges - or, to be more precise, the various actions of judges (their skills or specific ways of dealing with the ongoing interactions). Normative-based and non-normative-based innovations, as well as judgedependent and judge-independent innovations are crucial and useful distinctions. However, one can also try to identify criteria for other distinctions and kinds of innovations.

For example, one can try to conceptualize the distinction between innovations that are directly connected to power distance and innovations with an indirect connection to it. Ultimately, even though reconceptualized power distance, with its three levels, is already quite a broad concept, its actual functioning in different contexts seems to depend on such issues as the level of knowledge or understanding of what is happening that parties possess in a given interaction, or their levels of stress. It does not seem implausible to assume that a person who has little understanding of the peculiarities and specifics of a situation in which he or she engages in some asymmetrical social relationship with someone superior to him or her can interpret it in a completely different way from a situation with which he or she is already familiar. Having said that, 
one can start to think about innovations aimed at certain border conditions of specific power distance outcomes. In other words, if aspects such as knowledge levels or stress levels have some impact on power distance dynamics, they can become a site for innovations. Such innovations will not deal directly with power distance and its related aspects such as the underlying rules, the physical environment or the plethora of interpersonal communication features, but rather with other factors, which, although they can be regarded as relatively far removed from reconceptualized power distance, nevertheless still co-shape its particular dynamics in practice.

Of course, there are certainly other distinction criteria that can be proposed as well, but one could venture to say that the most important ones have already been suggested. Therefore, it is now possible to demonstrate which judicial innovation ideas can be derived from the research on power distance between judges and witnesses. As a result of the consistent focus on judges themselves in the discussed project, the remarks below are organized in accordance with the judge-dependent and judge-independent innovations. The other two distinctions relating to innovations will naturally be used as well. Moreover, this seems an appropriate juncture to stress that the following ideas all have their beginnings in the discussed project - especially the empirical research conducted in Kraków's Lower Court, and many of them were suggested by witnesses themselves. As the title of this paper suggests, the list below does not contain all derivable innovations. It is an illustrative, preliminary list that is meant to demonstrate the possibilities and general attractiveness of the proposed way of thinking. ${ }^{7}$ The latter can and should be developed, and this paper is only a first step. The first examples examined below relate to ideas for innovations independent of judges' behaviors.

\section{Chosen Examples of Judge-Independent Innovations}

First, with reference to the subjective (individual) level of power distance, it would be a very significant improvement for judges to have some knowledge about what is expected of them, in terms of interaction, by the various actors that visit their courtrooms during hearings. For example, a judge who has some advance knowledge of whether a particular witness's subjective (individual) power distance is low or high - whether the witness prefers a decrease or increase in power distance - could simply adjust his or her own behavior accordingly, thus contributing to an improvement of social opinions on judges. Leaving aside the obvious question here about the limits of such adjustments, one could say the following. The improvement of knowledge among judges about what kind of behaviors are socially expected of them could form the basis for certain further improvements. Consequently, as a specific innovation idea, one could consider conducting broad empirical research on a representative part of a given national population to diagnose its subjective (individual) power distance, especially with reference to the court environment. This would first require the preparation and testing of a usable scale to measure subjective (individual) power distance in the judicial context. Subsequently, empirical research should be conducted and its results properly presented to the judges' community in a given country. Such a demanding task could be

\footnotetext{
${ }^{7}$ It is up to possible further comparative research to determine whether presented proposals can be regarded as innovations also in other countries than Poland. It should be stressed though once again that the paper's aim is not comparative, but merely illustrative - how reconceptualized power distance can constitute a basis for judicial innovations.
} 
undertaken by the national ministries of justice, by non-governmental organizations, or within academic research projects. Due to its highly complex characteristics, such an innovative idea and enterprise can be regarded as independent of judges' behavior. It is also non-normative - such research does not require any changes in valid law. Moreover, since it is intended to acquire certain knowledge that can be used in actual courtroom interactions it can be regarded as innovation indirectly connected with power distance.

Second, during their observations in Kraków's Lower Court the research team members were struck by the fact that one court building, whose various courtrooms were designed in a similar fashion, was used as the place in which very different cases are tried. Both very serious criminal cases and petty civil law cases are tried within one and the same spatio-architectural environment. As a result, during case hearings, the parties to petty cases have to appear in a physical environment whose exterior, interior, and displayed symbols seem to increase power distance. As many contemporary examples from various countries demonstrate, it is possible to adopt a different approach to court building design (especially, Marks 2016). It is possible to design court buildings in accordance with the kind of cases that will be exclusively tried in that specific court. For example, buildings for criminal courts can be made more intimidating, whereas buildings in which relatively petty civil law cases are tried can be designed in such a way that the power distance within them is already visually, materially, and spatially flattened. Naturally, such an idea - which is also extremely demanding - is independent of judges' individual behavior. It can also be implemented without normative changes in black-letter law. However, unlike the first example, designing court buildings in accordance with the cases that will be tried in them seems to be directly connected to power distance. It was stated that asymmetrical social relationships take place within certain physical environments, and the way such environments appear and their general feel has a significance for power dynamics.

The third area to be considered relates to the courtrooms and case hearings. Having conducted a series of observations, research team members came to the conclusion that it would be valuable to provide certain basic information on court hearings to their lay participants in advance, particularly in relation to certain peculiarities that happen in courtrooms on a repetitive basis. In many cases, the observed and interviewed witnesses were appearing in court for the first time and were sometimes rather confused about what was happening. Their confusion could result in various reactions on the part of the judges, who may become irritated and consequently increase power distance through their gestures, eye-rolling, or increasing voice volume. One way to avoid that would be to prepare lay participants in advance. This could be done in a number of ways - for example, additional written or visual information could be provided with the individual summons to court (as in the case of witness summons) or at the door to the courtroom itself, or on the court's website. Again, due to the relative complexity of this idea and the fact that it depends on many different actors, it can be said to be ultimately independent of judges' individual behaviors. Certain forms of putting this innovation into practice could be done without changes to the written law. Moreover, this idea can be classified as being indirectly connected with power distance, since it relates to one border condition of particular power distance outcomes, i.e. knowledge. Unlike the first innovation, this one is not about the knowledge of judges, but rather the knowledge of those who are summoned to the court. Consideration could also be given to combining 
these two general ideas. Leaving this for another opportunity, one can now move directly into courtroom and address the fourth innovation idea.

Polish court procedure often requires written minutes of hearings to be prepared. In practice, judges tend to constantly paraphrase out loud what was said a minute earlier by the witness being questioned, so that a clerk can write it down. However, research team members also observed situations when the clerk was constantly writing down what was said by the witness, while the judge silently checked the minutes on the computer screen, without paraphrasing out loud. As one can easily imagine, the former situation is very uncomfortable. Constant interruptions of the witness by the judge in order to make a paraphrase for the clerk to transcribe significantly distort the ongoing communication and can even deepen the confusion of some witnesses. In fact, certain interviewees specifically complained about this. Moreover, as stated earlier, such confusion can have the further effect of leading to an increase in power distance. This got research team members thinking about the possibility of using or developing realtime voice recognition and automated or semi-automated transcription software to address the needs of the judiciary. Such an innovation would definitely have a positive impact on courtroom interactions. Naturally, this innovation is independent of judges, since it is unlikely that they could develop such software themselves. Whether the realization of this idea would require certain normative changes is open to discussion. Even though it is certainly closely related to courtroom interactional dynamics, this innovation can still be considered as indirectly connected with power distance. Ultimately, it is meant to enable a more natural flow of communication, thus reducing the risk of confusion among certain lay participants and its possible consequences.

The fifth example of an innovation idea seems to have a similar influence. The courtrooms visited by the research team members during the empirical research were frequently quite small. Naturally, there are also courtrooms that could be regarded as relatively larger and more spacious. A common feature of these two general kinds of courtrooms observed in Kraków's Lower Court is that the bench for people being questioned by the judge - especially witnesses - is situated relatively close to the judge's bench. Consequently, the field of vision of the person being questioned is taken up almost exclusively by the judge. In turn, when the parties to the case or their legal representatives are putting their questions to the person in the stand, the latter naturally has to turn his or her head to maintain eye contact with the person asking the questions. However, the replies to the questions must be addressed directly to the judge - which requires another turn of the head. It was observed by research team members that very often this subtle yet frequent aspect of case hearings caused confusion in witnesses and could trigger irritation among professionals present in the courtroom, including judges. Correcting the behavior of questioned witness can be regarded as increasing power distance, very often unnecessarily. In light of the above, and in view of the way courtroom space is arranged in some other European countries (e.g. Sweden, see Dahlberg 2009), one can propose simply moving the questioned person's bench away from the judge's bench. In effect, the questioned person's field of vision would then include both the judge and any other participants who may also be asking questions, thus obviating the necessity of any head-turning. In other words, moving the bench in question away from judge's bench could be regarded as a way of minimizing the confusion that is highly likely to arise among persons who are expected to listen to 
questions put by particular parties, but to respond to the judge. Increasing the field of vision to include all the parties with whom a person being questioned interacts or can interact in the courtroom would lead to much more natural and commonsensical interpersonal communication in the courtroom. It would minimize the risk of confusion on the part of the person being questioned and the possible consequences - especially the judge's demands for correct behavior, which could be regarded as increasing power distance and could even lead to a negative evaluation of the judge by the person who is questioned and corrected. Obvious issues, such as how practical or impractical it might be to actually shift the questioned person's bench in a given courtroom will not be addressed here; nor will the more basic idea that it may perhaps be preferable for the person being questioned by the judge to be focused on him or her exclusively, and that the closer the two benches are to one another, the better. What is more important here is to provide a basic conclusion about this particular idea. It is definitely judgeindependent (judges simply work with what they have at their disposal in a given courtroom) and non-normative (the exact positioning of the questioned person's bench seems to be so specific and detailed that it should not be subject to legal regulations, but one could not disallow a different approach either). Finally, it can also be regarded as innovation indirectly connected with power distance. It aims at modifying some feature of courtroom conditions so that certain situations that are confusing to lay participants do not happen; situations that can trigger power distance-increasing responses, especially from judges.

Without adding any other possible judge-independent innovation ideas derivable from reconceptualized power distance, it should be quite clear by now that one can come up with a plethora of scenarios on how to influence the power distance outcomes, even without proposing changes in the behavior of judges themselves, which are ultimately crucial to power distance dynamics. However, in order to complete the proposed presentation of the specific way of thinking about judicial innovations, grounded in reconceptualized power distance and the relevant empirical research, one should move on to innovation ideas that are not outside or peripheral to the various verbal and nonverbal behaviors of judges in the courtroom, but are dependent on them. As a result of this dependence, their complete number is even harder to imagine than the suggested judge-independent innovations. Still, some general idea about them can and should be given before the conclusion. Judge-dependent innovations derivable from reconceptualized power distance, as will be clear in a moment, are generally much more modest and less spectacular than innovations that are independent of judges. Ultimately, they all rest on the choices made by the judges themselves on how to behave in front of and with respect to other participants in the courtroom. However, in accordance with the presented research project, the following examples relate specifically to the judgewitness relationship. The research team members identified all these examples on the basis of the observations and interviews during the empirical stage of the project.

\section{Chosen Examples of Judge-Dependent Innovations}

First, research team members observed that it was not that uncommon for there to be delays in particular case hearings, especially when a previous hearing took longer than expected. In such cases, those waiting in the corridor for their hearing to begin can become quite irritated, especially when they are not provided with any explanation for 
the delay. Therefore, judges who are aware that there is a delay could ask the clerk present in the courtroom simply to inform the people in the corridor that the case hearing will begin after some delay. Naturally, judges cannot do this themselves, as they might still be hearing a previous case, and the clerk is, therefore, needed to act as a kind of proxy for the judge. While proposing such an easy solution to the judges might seem quite trivial, such an action on the part of a judge could nevertheless be regarded as relative innovation that is ultimately dependent on the judge's behavior (request to the clerk), non-normative (but potentially possible to regulate in writing) and indirectly connected to power distance. Ultimately, the clerk informing people in the corridor that there is some delay influences their broad understanding and knowledge of the situation with which they are faced. Moreover - and even more importantly - the result is achieved directly through the clerk, not the judge, who remains in the courtroom. However, if the judge takes some time at the outset to explain the reasons for the delay, and even apologizes for it, then this could definitely be regarded as an instance of direct influence on power distance dynamics. The judge is doing something that can be seen by other participants, especially witnesses, and his specific action contributes, with a plethora of other actions, in determining interactional power distance, which is naturally subject to evaluation accordingly to participants' subjective (individual) power distance. Again, one could venture to say that proposing to judges that they should undertake such an action and their realizations of such a proposal should be regarded as nonnormative innovation, but the possibility of this being encapsulated in a law cannot be ruled out.

Second, during observations, it was seen that even if multiple witnesses are summoned to participate in a given case hearing, they all are summoned to the court at the same time. As a result, it is possible for them to be questioned by the judge in official alphabetical order. Alternatively, at the beginning of the hearing, the judge could simply ask the witnesses whether any of them are in a hurry and would, therefore, like to be questioned first. The latter is a very simple tool for judges to use in order to present themselves as more humane and less bureaucratic; moreover, it can ultimately contribute to a decrease in power distance. Proposing and implementing such behavior can, therefore, be regarded as a really basic, simple innovation that is definitely judgedependent, non-normative (but with the potential to be regulated) and directly connected to power distance.

A similar evaluation can be found in the case of the third example. As stated earlier, witnesses questioned by the judge are supposed to stand still behind their stand. Such a position can be quite tiring in the case of extended questioning, or when a person being questioned is of significant age. Judges could either simply ignore such a situation or ask a witness whether he or she would like to take a seat. If this question is answered in the affirmative, the judge could request a clerk to prepare a seat for the witness. Again, such subtle and simple behavior on the part of a judge can be regarded as judge-dependent innovation that directly influences power distance. If the judge makes it possible for the witness to sit and not remain standing before him or her, the judge can definitely be said to be flattening the asymmetry between him or her and the witness - both are now seated; not only judge. It is open to further discussion whether such a scenario and its realization have or should have some normative grounding in, for example, procedural law or specific regulations. 
As is evident from these three simple examples, judge-dependent innovations derivable from reconceptualized power distance often seem to relate to the general responsiveness of judges to witnesses and the specific circumstances in which they happen to be. Accordingly, in addition to the rather specific first, second, and third examples, one can now move on to identify the fourth, more general innovation idea, which is also ultimately up to judges themselves. Research team members observed that certain judges are fairly consistent in their use of relatively formal language and expressions, or in making certain assumptions without explaining them to witnesses, who are often confused, whereas other judges are more flexible and accommodating. For example, in the case of a witness misunderstanding some part of a question or the current discussion, certain judges take considerable time to explain the relevant issue to the witness in clear and non-professional language, by rephrasing or even using the same words as the witness. If such behaviors are coherently coupled with active listening - for example by maintaining eye contact, encouraging nodding, and a gentle smile - then it seems safe to say that they are directly related to decreasing power distance. In effect, they participate in the realization of some procedural principle or in developing, maintaining, or changing social attitudes towards the judiciary. In summary, making judges fully aware of such simple behavioral tools, coupled with their actual, reflexive or deliberate use by judges, can be regarded as a type of innovation that can be successfully implemented without any black-letter law or institutional changes.

It should be acknowledged here that the above does not even constitute the tip of the iceberg when it comes to judge-dependent innovations that can be inferred from reconceptualized power distance. It is only through further dedicated research that a more specific list can be provided. Before such a task can be taken up by researchers, it is crucial to stress the following. Observations by the research team members demonstrate that the behaviors described in the above suggestions are actually exhibited by various judges in their courtroom practice. It could consequently be argued that the above examples do not relate to innovations after all. However, it is crucial to distinguish between behaviors that are exhibited by judges but are actually unintended and behaviors that result from reflexive, deliberate, and even strategic decisions by judges. In accordance with one of the theses constituting fundamental innovation described above, in order to deserve their name, judge-dependent innovations (possible to generate from power distance research) cannot take the form of accidental, unintended behaviors; they have to result from conscious decisions of judges. Moreover, if their decisions prove to be correct and adequate from the perspective of subjective (individual) power distance of participants in the hearing, then realization of certain important goals, such as given procedural principles or positive social opinions of the judiciary, can be made more certain than in a situation where there is a lack of such awareness among judges. From this perspective, the significance of the first judgeindependent innovation suggested above should be clearer, as well as the generally holistic character of thinking about judicial innovations proposed here.

\section{Conclusion}

This way of thinking can be criticized for merely attaching a new name to certain aspects relating to the judiciary, courts, courtrooms and judges which are already perfectly well known, and even taught and implemented. In response to such criticism it should be 
stressed that the presented way of thinking about judicial innovations derivable from reconceptualized power distance and the accompanying empirical research makes it possible to examine various factors that are crucial to the functioning of the judiciary (most significantly, normative, organizational, architectural, and behavioral factors) from a single, coherent, defined and theoretically grounded point of reference. Naturally, the modified understanding of power distance serves here as a common denominator for various innovations that can be thought of at the macro, meso, and micro levels of the judiciary as a whole, with special emphasis on the most subtle aspects of judges' behaviors in courtrooms. This point should be stressed, because although one can find in the literature certain ideas on how to improve the judiciary, as it is broadly understood, that are ultimately quite similar to the ideas presented above (e.g. Gold LaGratta 2015, Blake 2019), they do not specify in any manner even the most basic and important assumptions that underlie them. By contrast, the way of thinking proposed in this paper argues that it is not only specific innovation scenarios that are important, but also an awareness of deeper ideas that enable the generation of the former in the first place and explain them in detail. Ultimately, the approach proposed here not only makes it possible to grasp various kinds of innovations with one specific concept of power distance; it also clearly recognizes, as one of its consequences, that even the tiniest details of a judge's verbal and nonverbal behavior in the courtroom are highly significant for the realization of procedural principles, and the creation, maintenance and change of certain attitudes towards the justice system, and judges in particular.

Consequently, there are at least two major differences between the proposed approach and other ideas about judicial innovations. First, even though some may say that the proposed way of thinking is relatively simple, and perhaps even unsophisticated, a review of other judicial innovation studies demonstrates that they seem to be in a specific theoretical vacuum, in a sense of not being grounded in some specific established concepts, theories or frameworks of broadly understood social sciences. Some of them do not even attempt to present a tentative definition of judicial innovation or their points of departure and underlying assumptions. Second, as was stated earlier, this lack of a serious theoretical and conceptual grounding has the result that very often the multidimensional role and significance of individual judges and their behaviors in improving the judiciary is simply not stressed enough. By contrast, the proposed way of thinking provides one coherent, theoretical framework, grounded in particular established concept from social sciences (the reconceptualized power distance), to look through at judicial innovations, whose understanding, even if still rather general, is nevertheless explicitly stated (a deliberate change improving the judiciary with respect to realization of specific principles and provoking positive response from the public opinion, with the proviso that between these two general aims to be accomplished through innovation there may be some tensions). Moreover, the introduced approach can be regarded as aimed at fully recognizing judges and their behaviors as sources, sites and actors of innovations, in addition to the usual legislative, organizational, and technological approaches. Thankfully there are noticeable instances where the professional education of judges addresses such details as verbal and nonverbal behavior in their work (for example, in the Polish professional education of future judges, see Program Aplikacji Sędziowskiej [Judicial Application Program] (2018), by the Polish National School of Judiciary and Public Prosecution [Krajowa Szkoła 
Sądownictwa i Prokuratury]), but one wonders whether such programs examine why such details are so important (is there a single framework provided for that?), and, more importantly, whether it is stressed strongly enough that these details can and should be purposefully, reflexively managed by judges themselves in the course of their everyday work. The proposed way of thinking aims at making all this explicit and ultimately useable. However, it is still only a beginning. A general (but not too general) framework or scaffolding has been created. Now it must be completed.

\section{References}

Barendrecht, M., et al., 2018. Understanding Justice Needs: The Elephant in the Courtroom [online]. The Hague Institute for Innovation of Law. Available from: https://www.hiil.org/wp-content/uploads/2018/11/HiiL-Understanding-JusticeNeeds-The-Elephant-in-the-Courtroom.pdf [Accessed 8 November 2019].

Bednarek, G.A., 2014. Polish vs. American Courtroom Discourse: Inquisitorial and Adversarial Procedures of Witness Examination in Criminal Trials [online]. Basingstoke: Palgrave Macmillan. Available from: https://doi.org/10.1057/9781137414250 [Accessed 8 November 2019].

Bladowski, B., 2013. Metodyka pracy sędziego cywilisty [Methodology of Judge's Work in Civil Cases]. $4^{\text {th }}$ ed. Warsaw: Wolters Kluwer.

Blake, N., 2019. Understanding Courts. A Report by JUSTICE [online]. London: JUSTICE. Available from: https://2bquk8cdew6192tsu41lay8t-wpengine.netdnassl.com/wp-content/uploads/2019/01/Understanding-Courts.pdf [Accessed 8 November 2019].

Botero, J.C., et al., 2003. Judicial Reform. The World Bank Research Observer [online], 18(1), 61-88. Available from: https://doi.org/10.1093/wbro/lkg005 [Accessed 11 December 2019].

Bowen, P., and Whitehead, S., 2013. Better Courts: Cutting Crime Through Court Innovation [online]. London: New Economics Foundation/Centre for Justice Innovation. Available from:

https://www.courtinnovation.org/sites/default/files/documents/Better\%20Courts. pdf [Accessed 8 November 2019].

Burnett, A., and Badzinski, D.M., 2005. Judge Nonverbal Communication on Trial: Do Mock Trial Jurors Notice? Journal of Communication [online], 55(2), 209-224. Available from: https://doi.org/10.1111/j.1460-2466.2005.tb02668.x [Accessed 8 November 2019].

CBOS, 2017. Evaluation of the judiciary [online]. Warsaw: Centrum Badania Opinii Publicznej [The Public Opinion Research Center]. Available from: https://www.cbos.pl/EN/publications/reports/2017/031 17.pdf [Accessed 8 November 2019].

Clarke, D., 2014. Judicial innovation in Chinese corporate law [online]. In: J.O. Haley and T. Takenaka, eds., Legal Innovations in Asia: Judicial Lawmaking and the Influence of Comparative Law. Cheltenham: Edward Elgar, 259-272. Available from: https://doi.org/10.4337/9781783472796.00024 [Accessed 11 December 2019]. 
Conley, J.M., and O'Barr, W.M., 1990. Rules versus Relationships: The Ethnography of Legal Discourse. Chicago/London: The University of Chicago Press.

Dahlberg, L., 2009. Emotional Tropes in the Courtroom: On Representation of Affect and Emotion in Legal Court Proceedings. Law and Humanities [online], 3(2), 175205. Available from: https://doi.org/10.1080/17521483.2009.11423767 [Accessed 8 November 2019].

de Londras, F., 2017. In defense of judicial innovation and constitutional evolution [online]. In: L. Cahillane, J. Gallen and T. Hickey, eds., Judges, Politics and the Irish Constitution. Manchester University Press, 9-28. Available from: https://doi.org/10.7228/manchester/9781526114556.003.0002 [Accessed 8 November 2019].

de Savornin Lohman, A.F., and van Straalen, J., 2018. Sustainable Justice, A Social Responsible Focus on Innovation in Justice [online]. In: T. Sourdin and A. Zariski, eds., The Responsive Judge: International Perspectives. Singapore: Springer, 143-171. Available from: https://doi.org/10.1007/978-981-13-1023-2 6 [Accessed 8 November 2019].

Eisenberg, D.T., 2016. Reflections on "Innovations in Family Dispute Resolution". Maryland Law Review Endnotes [online], 75, 1-8. Available from: https://digitalcommons.law.umaryland.edu/cgi/viewcontent.cgi?article=2564\&co ntext=fac pubs [Accessed 8 November 2019].

Feeley, M.M., 2013. Court Reform on Trial: Why Simple Solutions Fail. With new foreword by Greg Berman. New Orleans: Quid Pro Books.

Freiberg, A., 2004. Innovations in the Court System [online]. Conference Paper.

Melbourne: Crime in Australia: International Conference, 29-30 November 2004. Available from:

https://www.academia.edu/7107106/INNOVATIONS IN THE COURT SYSTE M [Accessed 8 November 2019].

Godin, B., 2015. Innovation: A Study in the Rehabilitation of a Concept. Contributions to the History of Concepts [online], 10(1), 45-68. Available from: https://doi.org/10.3167/choc.2015.100103 [Accessed 8 November 2019].

Gold LaGratta, E., 2015. Procedural Justice: Practical Tips for Courts [online]. New York: Center for Court Innovation. October. Available from: https://www.courtinnovation.org/sites/default/files/documents/P I Practical Tip s.pdf [Accessed 8 November 2019].

Hofstede, G., 2001. Culture's Consequences: Comparing Values, Behaviors, Institutions, and Organizations Across Nations. $2^{\text {nd }}$ ed. Thousand Oaks: Sage.

Hofstede, G., Hofstede, G.J., and Minkov, M., 2010. Cultures and Organizations. Software of the Mind: Intercultural Cooperation and Its Importance for Survival. Revised and expanded $3^{\text {rd }}$ ed. New York: McGraw-Hill.

Krajowa Szkoła Sądownictwa i Prokuratury [Polish National School of Judiciary and Public Prosecution], 2018. Program Aplikacji Sędziowskiej [Judicial Application Program] [online]. Available from: 
https://www.kssip.gov.pl/sites/default/files/program aplikacji sedziowskiej 0.pd f [Accessed 8 November 2019].

Lepore, L., Borrello, L., and Alvino, F., 2012. ICT and Judicial Administration: A Model for the Classification of E-Justice Innovations [online]. In: M. De Marco et al., eds., Information Systems: Crossroads for Organization, Management, Accounting and Engineering. Berlin: Springer, 339-347. Available from: https://doi.org/10.1007/9783-7908-2789-7 38 [Accessed 8 November 2019].

Machura, S., 2007. Lay Assessors of German Administrative Courts: Fairness, PowerDistance Orientation, and Deliberation Activity. Journal of Empirical Legal Studies [online], 4(2), 331-363. Available from: https://doi.org/10.1111/j.17401461.2007.00091.x [Accessed 8 November 2019].

Marks, A., 2016. What is a Court? A Report by JUSTICE [online]. London: JUSTICE. Available from: https://2bquk8cdew6192tsu41lay8t-wpengine.netdnassl.com/wp-content/uploads/2016/05/IUSTICE-What-is-a-Court-Report-2016.pdf [Accessed 8 November 2019].

Miller, K., 2015. Disruption, Innovation and Change: The Future of the Legal Profession [online]. Report. Law Institute Victoria, December. Available from: https://www.liv.asn.au/Flipbooks/Disruption--Innovation-and-Change--TheFuture-of-t.aspx [Accessed 8 November 2019].

Mulcahy, L., 2011. Legal Architecture: Justice, Due Process and the Place of Law [online]. Abingdon: Routledge. Available from: https://doi.org/10.4324/9780203836248 [Accessed 11 December 2019].

Nakata, C., ed., 2009. Beyond Hofstede: Culture Frameworks for Global Marketing and Management [online]. New York: Palgrave Macmillan. Available from: https://doi.org/10.1057/9780230240834 [Accessed 8 November 2019].

Ostrom, B.J., et al., 2007. Trial Courts as Organizations. Philadelphia: Temple University Press.

Pałecki, K., 2003. Wprowadzenie do normatywnej teorii władzy politycznej [Introduction to normative theory of political power]. In: B. Szmulik and M. Żmigrodzki, eds., Wprowadzenie do nauki o państwie i polityce [Introduction to science on state and politics]. Lublin: Wydawnictwo Uniwersytetu Marii CurieSkłodowskiej, 183-217.

Richardson, E., Spencer, P., and Wexler, D., 2016. The International Framework for Court Excellence and therapeutic jurisprudence: Creating excellent court and enhancing wellbeing. Journal of Judicial Administration, 25, 148-166.

Roach Anleu, S., et al., 2016. Observing judicial work and emotions: using two researchers. Qualitative Research [online], 16(4), 375-391. Available from: https://doi.org/10.1177/1468794115579475 [Accessed 8 November 2019].

Samborski, E., 2013. Zarys metodyki pracy sędziego w sprawach karnych [An Outline of Methodology of Judge's Work in Criminal Cases]. $6^{\text {th }}$ ed., update by W. Kotowski. Warsaw: LexisNexis. 
Senge, P.M., 2006. The Fifth Discipline: The Art and Practice of the Learning Organization. Revised and updated ed. New York/London/Toronto/Sydney/Auckland: Doubleday.

Senge, P.M., et al., 1994. The Fifth Discipline Fieldbook: Strategies and Tools for Building a Learning Organization. New York/London/Toronto/Sydney/Auckland: Doubleday.

Świecki, D., 2012. Metodyka pracy sędziego w sprawach o wykroczenia [Methodology of Judge's Work in Offense Cases]. $2^{\text {nd }}$ ed. Warsaw: Wolters Kluwer. 